\title{
Normal and histopathological organization of the opercular bone and vertebrae in gilthead sea bream Sparus aurata
}

\author{
Juan B. Ortiz-Delgado ${ }^{1, *}$, Ignacio Fernández ${ }^{2,3}$, Carmen Sarasquete $^{1}$, Enric Gisbert ${ }^{2}$ \\ ${ }^{1}$ Instituto de Ciencias Marinas de Andalucía-ICMAN/CSIC, Campus Universitario Río San Pedro, Apdo. Oficial, 11510, \\ Puerto Real, Cádiz, Spain \\ ${ }^{2}$ IRTA, Centre de Sant Carles de la Ràpita (IRTA-SCR), Unitat de Cultius Experimentals, Crta. del Poble Nou s/n, \\ 43540 Sant Carles de la Ràpita, Spain \\ ${ }^{3}$ Centre of Marine Sciences (CCMAR), University of Algarve, Campus de Gambelas, 8005-139 Faro, Portugal
}

\begin{abstract}
This study provides a comprehensive description of the tissue organization of nondeformed and deformed opercula and vertebrae from gilthead sea bream Sparus aurata juveniles by means of histological, histochemical and immunohistochemical approaches. Two types of opercular anomalies are described: the folding of the opercle and subopercle into the gill chamber, starting at the upper corner of the branchial cleft and extending down to its lower third; and the partial lack of the operculum (opercle, subopercle, interopercle and preopercle underdeveloped) with a regression of the loose edge extending down to its lower third. Histological observations revealed a rare type of bone remodelling process in the opercular structure, which consisted of the coalescence of contacting bone tissues (presumably from the preopercle and opercle), resulting in skeletal tissue with a trabecular aspect filled by a single-cell epithelium of cubic osteoblastic-like cells. Differences in collagen fiber thickness and its 3-dimensional arrangement between normal and deformed opercula were also found. Lordotic vertebrae were characterized by the formation of fibrous cartilage in the haemal and/or neural sides, indicating that a metaplastic shift occurred during the process of lordosis. Another major histomorphological change found in lordotic vertebrae was the complete loss of notochordal sheath integrity. Histological alterations were coupled with an imbalance of cell death and cell proliferation processes in lordotic vertebrae as well as that of bone formation/resorption, and extracellular matrix deposition activity differences which might have resulted from the remodelling process occurring in lordotic vertebrae. Altogether, these results provide an increase in our basic knowledge of bone disorders that contribute to our understanding of the mechanisms by which these skeletal anomalies appear in this fish species and which hamper its production efficiency.
\end{abstract}

KEY WORDS: Bone $\cdot$ Extracellular matrix $\cdot$ Histology $\cdot$ Histochemistry $\cdot$ Immunohistochemistry · Skeletal deformities

\section{INTRODUCTION}

During the last decades, the finfish larviculture industry has considerably improved its rearing methods under intensive conditions, but larval quality remains one of the main problems for the proper sus-

\footnotetext{
${ }^{*}$ Corresponding author: juanbosco.ortiz@icman.csic.es
}

tainable success of this productive sector (Koumoundouros 2010, Boglione et al. 2013a). The quality of farmed fish is directly related to the quality of the fry, and depends on both organoleptic and morphological characteristics that should be as similar as possible to that of wild fish, which is considered to be the 
quality reference by the consumer. In this sense, an anomalous external morphology (even of a few fish) could substantially decrease the consumers' overall perception of aquaculture products (Boglione et al. 2013a). Skeletal deformities have been reported in natural environments (Gavaia et al. 2009, Diggles 2013), but with lower prevalence than in intensive aquaculture. The high incidence of skeletal deformities found in farmed fish (affecting up to $30 \%$ of production) might be due to (1) the absence of predators and the constant and high availability of food, which maximizes fish survival, or (2) that industrial hatcheries still lack the proper knowledge of how to produce high-quality and healthy fry under intensive rearing conditions in order to reduce the causative factors by which skeletal deformities are induced (Boglione et al. 2013a,b). However, since in all reared batches the skeletal deformity incidences are largely different, whether the fish come from the same or from different industrial hatcheries, the second hypothesis seems more plausible. Nevertheless, skeletal deformities are one of the most significant biological and recurrent problems affecting worldwide finfish aquaculture (see reviews in Koumoundouros 2010, Boglione et al. 2013a, Cobcroft \& Battaglene 2013).

Fish skeletogenesis involves the activity of 3 main cell types: chondrocytes, osteoblasts and osteoclasts (see review in Boglione et al. 2013b). The first 2 cell types secrete the extracellular matrix proteins of the cartilage and bone, respectively, while the third type produces cathepsins, matrix metalloproteinases and tartrate-resistant acid phosphatase (TRAP), providing an acidic environment in which the mineralized matrix is broken down (Ytteborg et al. 2010). In addition, skeletogenesis involves a fourth type of cell: the osteocytes, which are involved in maintaining bone matrix and acting as mechanical load receptors. In teleosts, the lack of osteocytes (acellular bone, a feature of the Sparidae family) implies that induced bone remodelling by mechanical load is triggered by cell types other than osteocytes (reviewed in Boglione et al. 2013a). Bone formation is brought about by a complex set of tightly regulated molecular pathways, involving extracellular matrix (ECM) constituents (e.g. alkaline phosphatase, ALP) or non-collagenous proteins such as the matrix Gla protein (MGP) or osteocalcin (OC), signalling molecules (e.g. hedgehogs and bone morphogenetic proteins) and transcription factors (Karsenty 2001, Boglione et al. 2013b). Hence, the perturbation of some of the above-mentioned factors in controlling bone development and homeostasis, as well as the incapacity of homeorhetic mechanisms to compensate for stressful environmen- tal conditions, may disrupt skeletogenesis, ultimately leading to the appearance of skeletal deformities (Boglione et al. 2013a). With the exception of environmental contaminants and pathogens (which are generally controlled under rearing conditions), different studies suggest that unfavourable environmental biotic and abiotic conditions, inappropriate nutrition and/or genetic factors are the most probable causative agents of skeletal abnormalities in reared fish (reviewed in Boglione et al. 2013b). Previous studies have indicated that skeletal anomalies are mainly induced in early stages of development (i.e. during embryonic and larval periods), occurring long before osteological deformities are externally visible (Daoulas et al. 1991, Koumoundouros et al. 1997a,b, Gavaia et al. 2009, Boglione et al. 2013b). Nevertheless, skeletal deformities could also be induced at later stages during the nursery phase (Boglione et al. 2013a). Regardless of when skeletal deformities are diagnosed, at juvenile or later stages of development (on-growing phase), it is difficult to gather information about their onset and aetiology since this is considered a multifactorial problem (Witten et al. 2005, 2006, Boglione et al. 2013a).

Although gilthead sea bream Sparus aurata L. is one of the most important species in European aquaculture, cranial and spinal abnormalities are still one of the major problems that hinder the efficiency of the production cycle of this sparid species. Vertebral deformities related to the non-inflation of the swimbladder (mostly lordosis) were the most frequent abnormalities recorded at the beginning of gilthead sea bream intensive culture (1980s and early 1990s) (Chatain 1994, Andrades et al. 1996). Although the improvement and refinement of rearing techniques have considerably reduced the frequency of these types of deformities (Boglione et al. 2013a), lordosis and kyphosis are still 2 of the most relevant osteological abnormalities observed in the axial skeleton of reared gilthead sea bream, while a partial and/or total lack of operculum is the most frequent anomaly affecting its cranial region (Koumoundouros et al. 1997b, Boglione et al. 2001, 2013b, Beraldo et al. 2003, Verhaegen et al. 2007, Castro et al. 2008, Koumoundouros 2010, Prestinicola et al. 2013). Several studies have described skeletogenesis in gilthead sea bream (Faustino \& Power 1998, 1999, 2001) and the typology of fish skeletal deformities (Witten et al. 2009, Boglione et al. 2013b, Prestinicola et al. 2013, among others) in order to better understand the phases of skeletogenesis and the effects of biotic and abiotic factors on the proper development of bone and the appearance of skeletal anomalies. Various 
procedures have been used as simple and rapid diagnostic tools for studying skeletal deformities in fish, such as X-rays, double staining or even computer tomography; allowing the identification of abnormal growth in different skeletal structures (see reviews in Witten et al. 2009, Koumoundouros 2010, Boglione et al. 2013b). Although there is a great variety of research in fish skeletal histology (reviewed in Meunier 2011), there is limited information about the histological organization of skeletal tissues in gilthead sea bream (Galeotti et al. 2000, Beraldo et al. 2003, Fernández et al. 2012). The use of histological procedures is considered a valuable tool for providing basic knowledge on bone formation, as well as providing new insights into the structural changes occurring in deformed skeletal structures (Ytteborg et al. 2012).

The aim of this study was to perform a comparative analysis of the tissue organization and distribution, as well as changes in ECM composition, between normal and deformed opercular bones and vertebrae from hatchery-reared gilthead sea bream juveniles. This description was conducted by means of histological, histochemical and immunohistochemical approaches in order to unveil the organization of these skeletal structures and the possible mechanisms by which the above-mentioned skeletal disorders develop.

\section{MATERIALS AND METHODS}

\footnotetext{
Animals

Gilthead sea bream larvae were reared under standard conditions in two $500 \mathrm{l}$ cylindroconical tanks

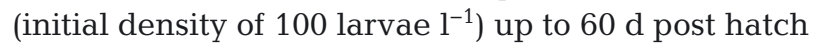
(dph) as described in Fernández et al. (2008). At that age (ca. 80 to $100 \mathrm{mg}$ wet body weight), fry were reared in a $2000 \mathrm{l}$ tank connected to a recirculation unit (IRTAmar ${ }^{\mathrm{TM}}$ ) until they weighted ca. $2 \mathrm{~g}$ (90 dph). During this period, fish were fed commercial diets following standard procedures according to Ortega (2008). Water conditions were as follows: 18 to $19^{\circ} \mathrm{C}_{i} 35 \mathrm{ppt}$ salinity; $\mathrm{pH}$ between 7.8 and 8.2 ; daily water renewal in the rearing tank was $20 \%$, and the tank had gentle aeration (oxygen levels $=6.2 \pm$ $1.1 \mathrm{mg} \mathrm{l}^{-1}$ ). Photoperiod was 12:12 h light:dark, and the light intensity at water surface was 500 lux. From $90 \mathrm{dph}$, fish were kept in an outdoor open-flow $14000 \mathrm{l}$ tank until they were 10 mo old $(35.5 \pm 15 \mathrm{~g}$ body weight, $10.5 \pm 1.5 \mathrm{~cm}$ standard length). During this period, fish were subjected to natural conditions in terms of thermo- and photoperiod regimes. The overall survival rate of the complete rearing process was estimated at ca. 15 to $20 \%$.
}

After a visual examination of 1064 live specimens in sorting tasks, normal and deformed specimens with underdeveloped operculum and lordosis were sampled ( 7 specimens for each morphotype), sacrificed with an overdose of anaesthetic (tricaine methanesulfonate, MS-222; Sigma-Aldrich) and dissected.

\section{Histological, histochemical and immunohistochemical procedures}

Normal and deformed opercula and vertebral centra were fixed in $4 \%$ buffered paraformaldehyde (in phosphate buffer saline, $\mathrm{PBS}_{;} \mathrm{pH}$ 7.4). After fixation, samples were washed in PTW (1\% PBS, 0.1\% Tween-20) 3 times for 30 min each, then either preserved in methanol at $-20^{\circ} \mathrm{C}$ or immersed for decalcification in a $10 \%$ EDTA $/ 2 \%$ formaldehyde solution at $4^{\circ} \mathrm{C}$ for $7 \mathrm{~d}$, followed by washes in PTW as described above. After fixation and decalcification, samples were washed, embedded in paraffin and serially sectioned at 5 to $6 \mu \mathrm{m}$ thickness as previously described (Ortiz-Delgado et al. 2005). Undecalcified samples were subjected to the von Kossa staining method: a precipitation process in which silver ions react with phosphate in the presence of acidic medium (Clark 1981). The von Kossa staining method alone may not be sufficient to confirm mineralization, since it does not necessarily imply the presence of calcium or of hydroxyapatite, the mineral phase of bone (Bonewald et al. 2003). Although further evidence of bone mineralization may be needed using alternative procedures (Bonewald et al. 2003), in the present study, and considering morphological and molecular data from Tiago et al. (2011), we used von Kossa staining as a first approximation for whether structures were mineralized or not.

For studying ECM components of bone tissue and cartilage, adjacent sections were stained with the following techniques: haematoxylin and eosin (H/E) for histomorphological observation, orcein for elastic fibers, van Gieson trichrome and picrosirius red staining (PRS) for collagen, Mallory and haematoxylin/ VOF (H/VOF) trichrome (Gutiérrez 1967) for connective tissue and Alcian Blue (AB) 8GX (Sigma) at pH 2.5/periodic acid-Schiff (PAS) for acidic and neutral mucopolysaccharides. Dye affinity or intensity of the above-mentioned staining techniques from different regions of studied tissues was ranked by visual scoring by at least 2 trained observers (10 slices per technique and 5 sections per slice) as: negative (-), very weak $(+-)$, weak $(+)$, moderate $(++)$ and strong $(+++)$. Values were scored considering the accumula- 
tion levels of the dye for each considered vertebral part, and ranged from the absence of staining (negative) to the highest stain intensity (strong), whereas intermediate scoring staining categories were established as intermediate ranges among the abovementioned extreme scores. These protocols were conducted according to monographs by Martoja et al. (1970), Pearse (1985), Bancroft \& Stevens (1990) and Sarasquete \& Gutiérrez (2005). Additionally, PRS sections were observed under polarized light according to Junqueira et al. (1979) and Kiernan (2008). Briefly, after PRS and under bright field microscopy, collagen appears red on a pale yellow background. A BX41 Olympus light microscope equipped with 2 kinds of filters (a polarizer and an analyzer) was used to provide linearly polarized illumination. Digital images were obtained with a C3030 Olympus digital camera.

Bone remodelling/homeostasis, a dynamic process that relies on the correct balance between bone resorption by osteoclasts and bone deposition by osteoblasts (Boglione et al. 2013b) was described by means of staining for TRAP and ALP activities, respectively. Both enzyme activities were visualized with the acid and alkaline phosphatase leukocyte kits (Sigma-Aldrich) according to the instructions of the manufacturers.

Immunohistochemistry for ECM proteins was performed using a rabbit polyclonal antibody developed against $\mathrm{OC}$ and MGP from meagre (Argyrosomus regius Asso, 1801) as primary antibodies. Anti meagreOC and -MGP antibodies presented a specific cross reactivity for gilthead sea bream-OC and -MGP (Simes et al. 2004). Immunohistochemical staining was performed with peroxidase-conjugated antirabbit IgG (Sigma) as secondary antibody, using the methodology proposed by Simes et al. $(2003,2004)$. Briefly, serial sections were incubated overnight with anti-OC and anti-MGP primary antibodies at appropriate dilutions (1:500 for OC and 1:250 for MGP). After several washes in PBS, sections were incubated for $1 \mathrm{~h}$ with goat anti-rabbit IgG peroxidaseconjugated, and stained with 3-3'-diaminobenzidineDAB (Sigma). The endogenous peroxidase activity was blocked with $3 \% \mathrm{H}_{2} \mathrm{O}_{2}$ before staining. Sections incubated with normal fish serum instead of the primary antibody were used as negative controls.

Cell proliferation and apoptosis processes were also assessed by immunohistochemical detection of proliferating cell nuclear antigen (PCNA) and cleaved caspase-3, respectively. The former assays were performed as described by Bakke-McKellep et al. (2007) for PCNA and Sanden et al. (2005) for caspase-3, using a mouse anti-PCNA (Santa Cruz Biotechno- logy) and cleaved caspase-3 antibody (Cell Signalling), respectively. Sections incubated with normal fish serum instead of the primary antibody or without substrate incubation were used as negative controls. After staining, all sections were dehydrated by air drying and mounted with EUKITT (Labolan).

\section{RESULTS}

Macroscopically, we detected 2 types of opercular anomalies according to the classification previously described by Beraldo et al. (2003): (1) the folding of the operculum (opercle and subopercle) into the gill chamber, starting at the upper corner of the branchial cleft and extending down to its lower third (Type $I_{i}$ Fig. 1a), and (2) the partial lack of the operculum (lack of development of the opercle, subopercle, interopercle and preopercle) with a regression of the loose edge extending down to its lower third (Type II; Fig. 1b). The overall incidence of fish with deformed operculum was $6.3 \%$. These opercular abnormalities unilaterally affected both sides of the head: the right (3.3\%) and left (3.0\%) equally; whereas the bilateral abnormality in the operculum only affected $1.1 \%$ of the reared fish.

Fish with a severe external body shape deformity (Fig. 1c) showed internal lesions characterised by an accentuated ventral curvature (lordosis) of the vertebral column (Fig. 1d). The degree of these pathological symptoms varied along the vertebral column axis and mainly affected vertebrae located between the limit of pre-haemal and haemal areas of the vertebral column (position 11 to 15 from urostyle upwards). The incidence of fish affected by lordosis was $10.1 \%$.

\section{Histological organization of normal and deformed operculum}

The operculum is a complex structure composed of 4 distinct and articulated bony plates: the opercle, preopercle, interopercle and subopercle. At a histological level, the opercular complex of gilthead sea bream shows a regular succession of tissue layers: outer and inner skin layers, and an intermediate layer of bone (Fig. 2a). The posterior rim of the operculum is a flexible ribbed structure, which closes the gill cavity like a lid.

Transversal sections at the mid region of normal operculum stained with the PRS technique showed a preopercle mainly composed of highly trabeculated bony tissue, and a plate-like opercle with solid bone 

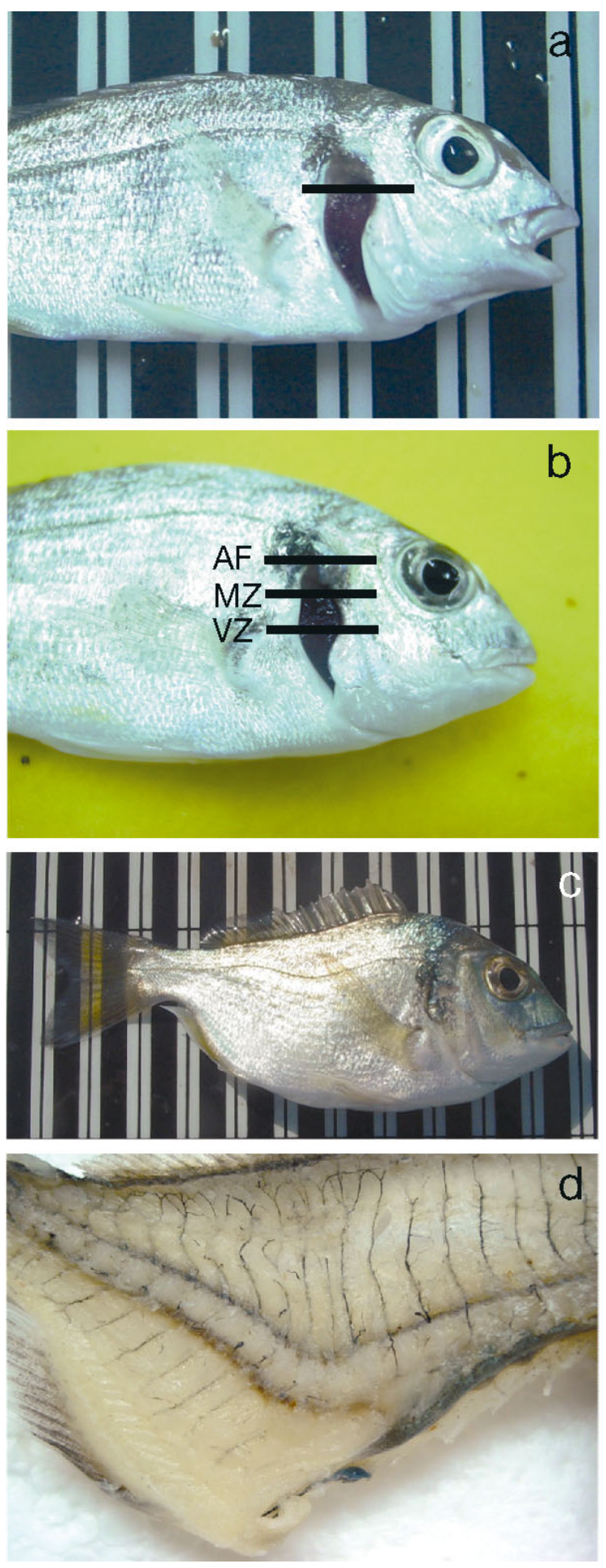

Fig. 1. Macroscopical appearance of deformed operculum and vertebra in gilthead sea bream Sparus aurata specimens. (a) Type I and (b) Type II opercular malformations and (c) external and (d) internal appearance of a lordotic fish. Note the accentuated ventral curvature and the upwards bending of vertebral column. Bars indicate the level of transversal dissected regions. Abbreviations: AF, articulatory facet; $\mathrm{MZ}$, medial zone; $\mathrm{VZ}$, ventral zone and homogeneous mineralisation levels (Fig. 2b-e, Table 1). The anterior rim showed medially directed trabecular projections at the level of the articulatory facet that were absent in the caudal direction (Fig. 2b,c). In addition, the PRS evidenced some differences in composition of both preopercle and opercle bones. While the preopercle had a predominant green colour with scarce areas of red (orange under polarized light), the opercle showed reticular fibers with a homogeneous greenish staining (green under polarized light) (Fig. 2d,e).

The 2 different patterns of opercular deformities reported in this study showed some differences with regards to the tissue layers involved in the osteological anomaly. The opercular Type I deformity corresponded to a folded operculum, directed towards the inside of the gill cavity. Although the deformed operculum affected all tissue layers, a severely curled opercle and/or subopercle concomitant with a proliferation of epithelial tissue within the folded area were detected (Fig. 2f,g). Additionally, hypoplasia of muscular fibers and enlargement of trabecular spaces in the rostral portion of the opercle were also observed. Polarized light revealed some differences in bone composition of normal and deformed opercula (e.g. changes in colour stain); the opercle and subopercle from deformed fish presented a brighter green colour than normal ones (Fig. 2g). In contrast, the opercular Type II deformity (Fig. $2 \mathrm{~h}-\mathrm{k}$ ) corresponded to a hypoplasic operculum in which some bone structures had disappeared depending on the dissected region (articulatory facet, medial and ventral zones; see Fig. 1b). For instance, the dissected operculum at the ventral zone showed a regression of the subopercle and a complete lack of the opercle. In this case, fibrous and epithelial cells proliferated and filled the empty space; thus, as a result of a lack of bone support, the outer and inner skin layers of the opercle folded into the gill cavity (Fig. 2h). At the medial opercular zone, the formation of an outward folding of the opercle was detected (H/VOF; Fig. 2i), as well as a thickening of the skin epithelium. Finally, the dissection of the dorsal area of the operculum revealed a modified articulatory facet in which a coalescence of contacting bony tissues was detected, as well as the formation of a chondroid bone-like structure. The trabecular structure of the opercle and subopercle was also modified; the trabecular spaces were filled with a single-cell epithelium (presumably osteoblasts) (Fig. $2 \mathrm{j}, \mathrm{k}$ ). All skeletal tissue involved in this deformity was ossified, as revealed by von Kossa staining (data not shown). 

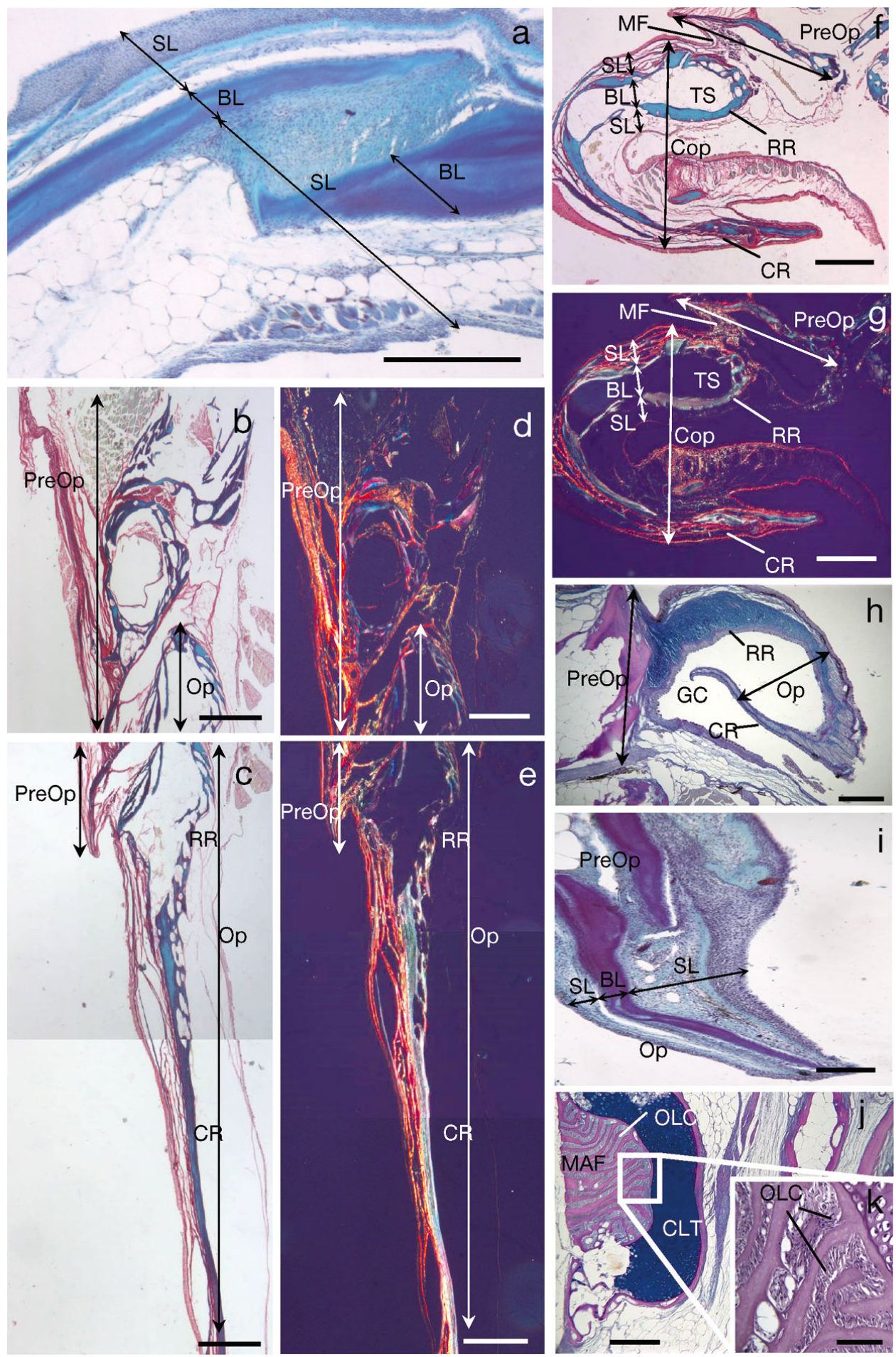

Fig. 2. Histological sections of (a-e) normal and (f-k) deformed opercula in gilthead sea bream Sparus aurata specimens. (a) Regular succession of skin and bone layers stained with H/VOF; $(b, c)$ transversal sections at the mid region of normal operculum showing the trabecular bone forming the preopercle and the rostral portion of opercle, and the plate-like solid bone forming the caudal region of the opercle; $(\mathrm{d}, \mathrm{e})$ mixture of red and green colour of the preopercular bone and the homogeneous greenish staining of the opercle under polarized light; micrographs of opercula deformities Type I and Type 2 with: picrosirius red staining under (f) non-polarized and (g) polarized light; H/VOF staining at (h) ventral and (i) medial zones, AB pH 2.5/PAS staining of $(\mathrm{j})$ the modified articulatory facet and $(\mathrm{k})$ its magnification of deformed $S$. aurata opercula. Scale bars $=50 \mu \mathrm{m}$. Abbreviations: BL, bone layer; Cop, curled operculum; CLT, cartilage-like tissue; CR, caudal region; GC, gill chamber; MF, muscle fibers; MAF, modified articulatory facet; OLC, osteoblastic-like cells; Op, opercle; PreOp, preopercle; RR, rostral region; SL, skin layer; TS, trabecular spaces 
Table 1. Staining properties of each part of the operculum in gilthead sea bream Sparus aurata. Staining intensity: (-) negative, (+-) very weak, (+) weak, (++) moderate, (+++) strong. See 'Materials and methods' for details

\begin{tabular}{|c|c|c|c|c|c|c|c|}
\hline & H/VOF & $\begin{array}{l}\text { van } \\
\text { Gieson }\end{array}$ & PAS & $\mathrm{AB}$ & $\begin{array}{l}\text { von } \\
\text { Kossa }\end{array}$ & Mallory & Orcein \\
\hline \multicolumn{8}{|l|}{ Preoperculum } \\
\hline Outer layer & Light green & Pink & $-/+-$ & - & - & Red & Brown \\
\hline Intermediate layer & Purple & Deep red & $-/+-$ & - & +++ & Blue & Pink \\
\hline Inner layer & Ligth green & Pink & +- & ++ & - & Red & Brown \\
\hline Operculum & & & & & & & \\
\hline $\begin{array}{l}\text { Outer layer } \\
\text { Intemediate layer }\end{array}$ & Light green & Pink & - & - & - & Red & Brown \\
\hline Rostral portion & Purple & Deep red & + & +- & $++/+++$ & Blue & Pink \\
\hline Caudal portion & Light purple & Red & + & +- & ++ & Blue & Pink \\
\hline Inner layer & Light green & Pink & - & - & - & Red & Brown \\
\hline Ribbed structure & Green & Light red & - & - & - & Orange & Brown \\
\hline
\end{tabular}

Table 2. Staining properties of each part of the vertebra in gilthead sea bream Sparus aurata. Staining intensity: $(-)$ negative, $(+-)$ very weak, $(+)$ weak, $(++)$ moderate, $(+++)$ strong. See 'Materials and methods' for details

\begin{tabular}{|c|c|c|c|c|c|c|c|}
\hline & $\mathrm{H} / \mathrm{VOF}$ & $\begin{array}{l}\text { van } \\
\text { Gieson }\end{array}$ & PAS & $\mathrm{AB}$ & $\begin{array}{l}\text { von } \\
\text { Kossa }\end{array}$ & Mallory & Orcein \\
\hline Notochord & Light green & Pink & $-/+-$ & - & - & Red & - \\
\hline $\begin{array}{l}\text { Surrounding notochordal } \\
\text { epithelial layer }\end{array}$ & Green & Light red & $-/+-$ & - & - & Red & - \\
\hline Secondary chordal sheath & Light Green & Pink & $-/+-$ & - & $+/++$ & Blue & Brown \\
\hline Primary chordal sheath & Green & Red & +- & ++ & - & Red & - \\
\hline Centrum & Purple & Deep red & $+-/+$ & - & +++ & Deep blue & Pink \\
\hline \multicolumn{8}{|l|}{ Intervertebral ligament } \\
\hline Notochordal sheath & Light green & Pink & + & + & - & Pink & - \\
\hline Elastic membrane & Purple & Pink & - & - & - & Blue & Brown \\
\hline Collagenous ligament & Light green & Red & - & - & - & Pink/red & Pink \\
\hline Osteoblasts & Purple & Red & - & - & - & Red & - \\
\hline Periosteum & Light green & Pink & - & +- & - & Red & Brown \\
\hline Arches & Blue & Deep red & + & + & ++ & Deep blue & Pink \\
\hline
\end{tabular}

\section{Histological organization of normal and deformed vertebrae}

The normal histological structure of transversal sections of the vertebral centra of gilthead sea bream stained with Mallory, van Gieson, H/VOF trichrome and PRS techniques showed a succession of tissue layers from the inner to the outer region. A central notochordal tissue (composed of chordoblasts and chordocytes) is surrounded of 2 fibrous layers (notochordal sheath), one composed of elastic fibers - the primary chorda sheath (Mallory trichrome-positive), and the other with mucopolysaccharides (ABpositive) and sparse collagen fibers - the secondary chorda sheath (van Gieson trichrome-positive)
(Table 2, Fig. 3a-c). The notochord sheath is enclosed by 2 different bone layers: a laminar and compact layer (internal; light green under polarized light) and a cancellous layer (external; green with large orange areas under polarized light). An osteogeneous tissue layer (osteoblast layer) and the periosteum complete the skeletal structure of the vertebral body (Fig. 3a-c). Neural and hemal arches are composed of chondral bone. These arches end in a spine composed of fibrous bone that projects into the myosepta (Fig. 3d). PRS stainings of transversal sections of normal vertebra visualized under polarized light exhibited some orange surfaces embedded in a bright green colour. The fibrous layer surrounding the bony structure also contained fine and sparse green colour regions (Fig. 3e).

Transversal sections of deformed vertebrae showed an alteration of the layered disposition with fibro/cellrich cartilage displacing cancellous and compact bone. Enlargement of trabecular spaces were also detected in lordotic vertebrae (Fig. 3f,g). Moreover, the notochordal lumen was reduced, with distorted chordocytes showing compression with a clear reduction in size (Mallory staining; Fig. 3f). Additionally, the PRS staining revealed some differences in the composition of the bone matrix between normal and deformed vertebrae. In general, and under a bright microscope, compact bone of deformed vertebra showed a red colour (immature bone) in contrast to normal vertebrae, in which compact bone stained green (mature bone) (Fig. 3d,e for normal vertebrae; Fig. 3h,i for deformed vertebrae). Moreover, under polarized light, deformed vertebra showed weak greenish staining (Fig. 3i). 

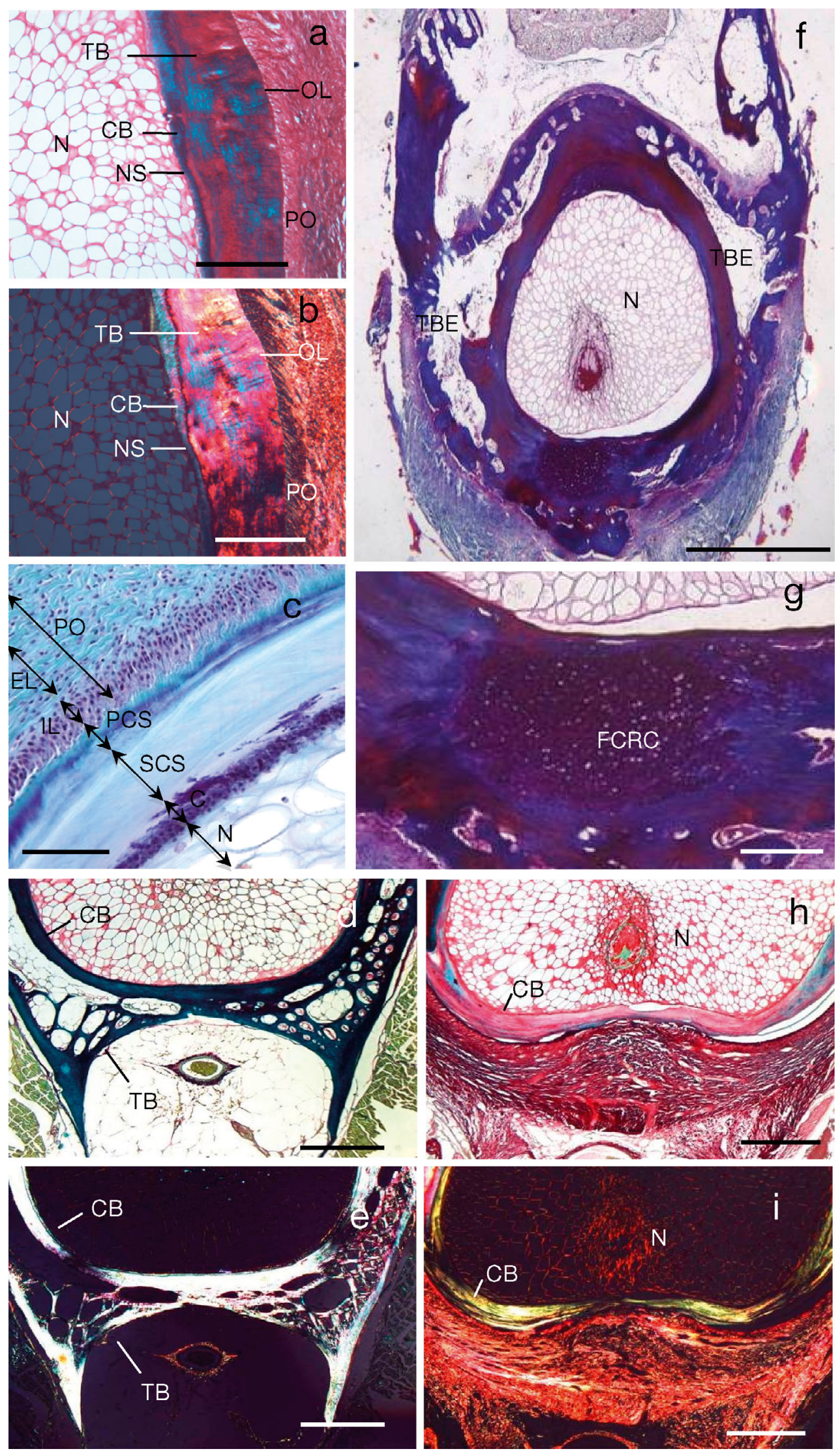

Fig. 3. Transversal sections of (a-e) normal and (f-i) deformed structure of vertebral tissue of gilthead sea bream Sparus aurata specimens. (a) Detailed visualization of the succession of tissue layers surrounding the notochord by pricrosirius red staining under nonpolarized light; (b) vertebral tissue stained with pricrosirius red and visualized under polarized light showing internal (compact bone, light green) and external bony layers (trabecular bone, green with big orange areas); (c) detail of the layered distribution of the chorda sheath surrounding the notochord with H/VOF staining and (d) of the trabecular bone forming the vertebral arches stained with pricrosirius red and visualized under non-polarized light. Note (e) the presence of some orange surfaces embedded in a bright green colour staining in vertebral arches with pricrosirius red technique visualized under polarized light. (f,g) Transversal section of deformed vertebra with Mallory staining. Note the presence of a fibrous cartilage replacing both cancellous and compact bone. Picrosirius red staining of deformed vertebra showing a weak greenish staining visualized under (h) non-polarized and (i) polarized light. Scale bars $=50 \mu \mathrm{m}$. Abbreviations: $\mathrm{C}$, chordoblasts; CB, compact bone; CL, collagenous ligament; EL, external layer FCRC, fibro/cell-rich cartilage; IL, internal layer; N, notochord; NS, notochordal sheath; OL, osteogenic layer; $\mathrm{PO}$, periosteumi $\mathrm{PCS}$, primary chorda sheath; SCS, secondary chorda sheath; $\mathrm{TB}$, trabecular bone; TBE, trabecular space enlargement 
Mediosagittal sections of normal vertebral centra stained with Mallory, van Gieson, H/VOF, orcein and PRS techniques (Fig. 4a-f) showed a central part of cancellous bone with a mesh of longitudinal and transverse trabecula, funnel-shaped vertebral end-plates and the so-called intervertebral ligaments
(Fig. 4a). The vertebral centrum was composed of a bone matrix with osteoblasts within cancellous lacunae, a periosteum consisting of an external layer of connective tissue rich in fibrillar elements, and an internal layer rich in cellular elements (osteogeneus tissue composed of osteoblasts; Fig. 4b). The inter-
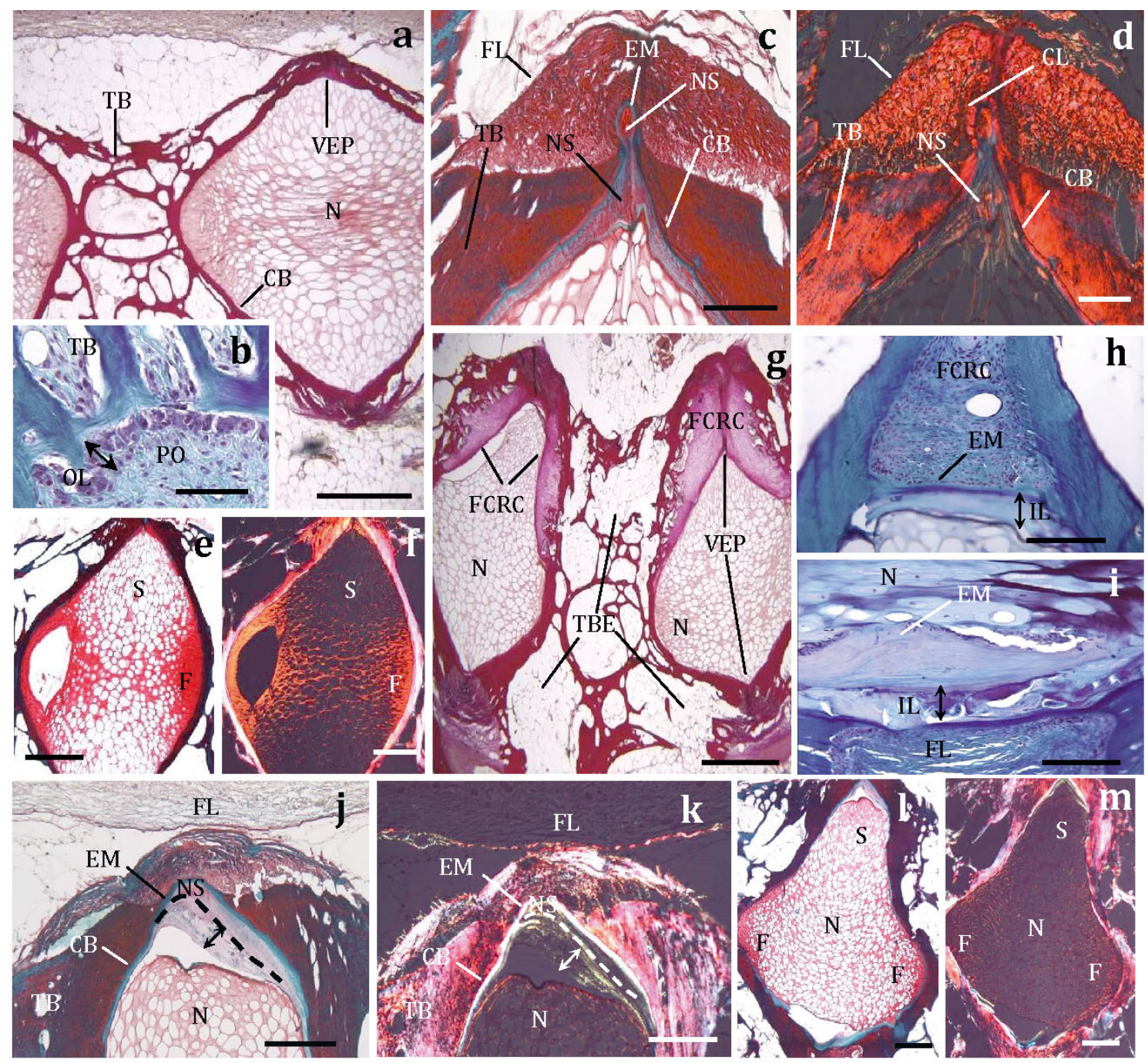

Fig. 4. Mediosagittal sections of (a-f) normal and $(g-m)$ deformed vertebra of Sparus aurata. (a) Central part of cancellous bone and vertebral end plates stained with van Gieson; (b) detail of the vertebral body comprising the bone matrix with osteoblasts within cancellous lacunae and the periosteum stained with H/VOF; detailed pictures of the intervertebral region showing its different layers stained with picrosirius red and visualized under (c) non-polarized and (d) polarized light (note the heterogeneous staining of the trabecular bone in contrast with the compact one). Detailed pictures of the fibrous and spongy layers of the notochord stained with picrosirius red and visualized under (e) non-polarized and (f) polarized light (note the presence of orange stained fibers within notochordal fibrous and spongy layers). Detail of the altered vertebral core with enlarged trabecular spaces and the presence of a fibrous connective tissue in the intervertebral region with (g) van Gieson and $(h, i)$ H/VOF stainings. Detailed micrograph of the intervertebral ligament of deformed vertebra showing a modification of the intervertebral ligament (double arrow) and of the fibrous layer stained with picrosirius red and visualized under (j) non-polarized and (k) polarized light. Note (l) the lesser proportion of the notochordal spongy layer in deformed vertebrae in comparison with normal ones with picrosirius red staining and visualized under non-polarized light and $(\mathrm{m})$ the lesser orange staining with picrosirius red technique and visualized under polarized light. Scale bars $=50 \mu \mathrm{m}$. Abbreviations: $\mathrm{CB}$, compact bone; CL, collagenous ligament; EM, elastic membrane; F, notochordal fibrous layer; FCRC, fibro/cell-rich cartilage; FL, fibrous layer; IL, intervertebral ligament; N, notochord; NS, notochordal sheath; OL, osteogenic layer; PO, periosteum; S, notochordal spongy layer; $\mathrm{TB}$, trabecular bone; TBE, trabecular space enlargement; VEP, vertebral end-plates 
vertebral ligament was composed of 3 acellular structural components: an inner notochordal sheath, a medial elastic membrane (orcein positive; Table 2) and an external sclerotome-derived collagenous ligament (Fig. 4c,d). Between each vertebra, the notochord tissue was composed of fibrous and spongy layers (Figs. 4e,f). Trabecular bone samples stained with PRS and visualized under polarized light had a heterogeneous composition consisting of a mixture of orange and green stainings, whereas compact bone exhibited a homogeneous composition (Fig. 4d). Notochordal fibrous and spongy layers also showed orange staining (Fig. 4f).

In comparison with normal vertebrae, the histological analysis of deformed vertebrae allowed the identification of a different tissue. Mediosagittal sections of deformed vertebrae showed an altered central part with enlarged trabecular spaces compared to normal vertebra. Moreover, affected vertebrae showed a pathological formation of fibro/cell-rich cartilage (stained pink with van Gieson's technique; Fig. 4g) replacing the notochordal and the cancellous acellular bone in the haemal or neural sides (H/VOF; Fig. 4h). In the opposite area of the same deformed vertebrae, a loss of the typical funnel-shaped bone end-plates, and a thickening of the intervertebral ligament and the external elastic membrane were also detected (H/VOF; Fig. 4i). In the intervertebral ligament of deformed vertebrae, an additional layer rich in orange staining was also visible filling the notochordal space. Moreover, abnormal vertebrae showed a lower orange staining surface on the fibrous layer of the growth zone of the bone endplates in comparison to normal vertebrae (Fig. 4j,k), and a lesser proportion of the notochordal spongy layer was detected in deformed vertebrae in comparison with normal ones (Fig. 4l,m).

\section{Histochemical and immunohistochemical analysis of OC and MGP proteins}

Immunohistochemical analyses revealed that OC and MGP proteins showed similar distribution in mineralized bone matrix in the normal (Fig. 5a) and deformed Type I (Fig. 5b,c) and Type II (Fig. 5d-f) opercula. Additionally, MGP was found in both mineralized bone matrix and cellular elements of the modified articulatory facet from the Type II deformity (Fig. 5e).

Considering the vertebral tissue, OC and MGP protein distribution presented some differences between normal and deformed structures both in the mineralized matrix and the notochordal tissue (OC or MGP immunostaining counterstained with $\mathrm{AB}$ pH 2.5 and H/VOF; Fig. 6a-p). In normal vertebrae, OC was homogeneously accumulated in the compact and cancellous bone matrix from the periosteal zone of the vertebral centra and in the arches, as well as in some osteoblasts located in the growth zone (Fig. 6a-c). In contrast, MGP preferentially accumulated in the notochordal cells, with minimal presence in the different bone layers (Fig. 6d). Deformed vertebrae showed a preferential deposition of OC in the compact bone layer compared with the cancellous one (Fig. 6e), as well as in the notochord (Fig. 6f), which coincided with von Kossa positive staining (Fig. 6g). In addition, a replacement of bone by cartilaginous tissue, showing glycosamineglycans instead of OC deposition, was detected in the lordotic compressed region (Fig. 6h). Regarding the vertebral bone endplates, some differences in OC distribution were also detected between normal and deformed vertebrae: OC was deposited in the intervertebral ligament and in the ring-like structure of non-deformed vertebrae, whereas it was undetectable in the same areas from deformed vertebrae. In addition to the thickening of the interverbebral ligament and the external elastic membrane, an accumulation of glycosamineglycans (AB positive) was also detected in these areas. Additionally, some differences in OC deposition were also detected in the fibrous layer of the growth zone and in the trabecular bone, being lower in OC content in deformed vertebra than in normal ones (Fig. 6i,j). Concerning MGP distribution in deformed vertebrae, a slight increase of staining intensity was detected in notochordal cells of deformed vertebrae (Fig. 6k,l).

Finally, histological observations revealed that osseous tissue was replaced by cartilaginous tissue rich in glycosaminoglycans in the intervertebral space of lordotic vertebrae (Fig. 6m,n). In a more advanced stage, the recently formed cartilaginous tissue accumulated $\mathrm{OC}$, and a new calcified matrix was formed (incipient fusion stage) (Fig. 6o,p).

\section{Bone homeostasis markers}

We analysed ALP and TRAP activities in both normal and deformed bone structures in order to identify cells responsible for bone deposition and resorption, respectively. However, our results did not show clear differences between non-deformed and deformed skeletal structures with regards to ALP activity (data not shown). TRAP activity in non-deformed vertebrae was distributed in the bone matrix of the trabec- 

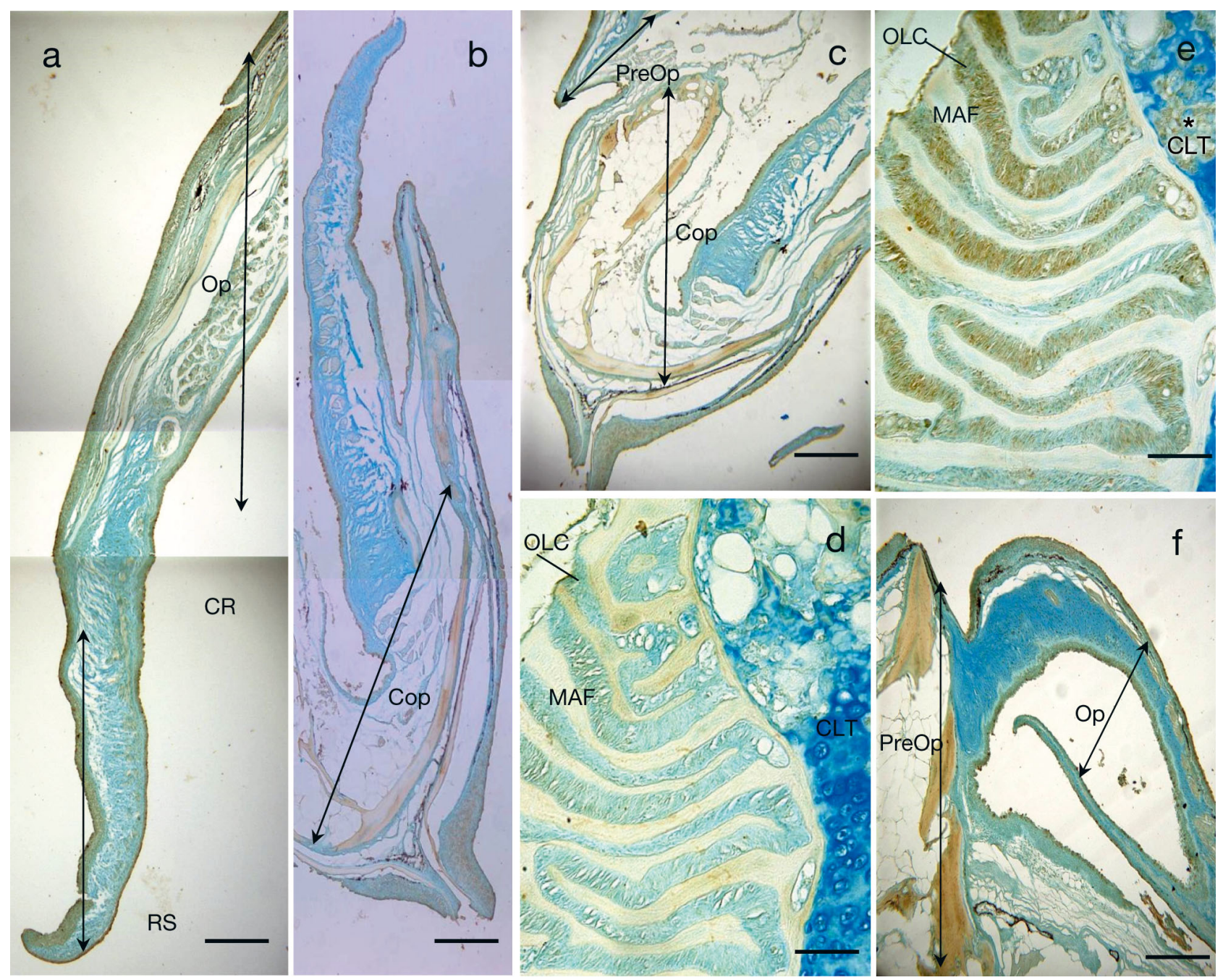

Fig. 5. Osteocalcin (OC) and matrix Gla protein (MGP) immunoreactivity counterstained with AB pH 2.5 in normal and deformed Sparus aurata opercular structures. (a) OC immunostaining in non-deformed operculum; (b) OC and (c) MGP immunostaining in bone opercular structures from Type I deformity. Note that no differences in OC or MGP protein distribution within the bone matrix could be detected. (d) OC and (e) MGP immunostaining in modified articulatory facet in an opercular Type II deformity. Note the presence of MGP protein both in cellular elements (osteoblastic-like cells from the articulatory facet and cells within cartilage-like tissue, ${ }^{*}$ ) and in calcified matrix from the modified articulatory facet. (f) OC immunostaining in an opercular Type II deformity at level of ventral zone. Scale bars $=50 \mu \mathrm{m}$. Abbreviations: CLT, cartilage-like tissue; Cop, curled operculum; CR, caudal region; MAF, modified articulatory facet; OLC, osteoblastic-like cells; Op, operculum; PreOp, preoperculum; RS, ribbed structure

ular region (Fig. 7a,b), as well as the osteoclasts within the trabecula lacunae and bone-reabsorbing fronts of normal vertebrae (Fig. $7 \mathrm{c}, \mathrm{d}$ ), but not in deformed ones (Fig. 7e). Moreover, an intense reaction for TRAP activity was exclusively detected in the chondrocytic areas of deformed vertebrae (Fig. 7f).

To determine whether the skeletal anomalies found in gilthead sea bream could be linked to an imbalance in cell cycling rather than to unbalanced cell activity, PCNA immunostaining was performed to measure cell proliferation, and a caspase- 3 assay was conducted to detect processes related to cellular apoptosis. Immunohistochemistry of PCNA showed differential distribution between normal and deformed vertebral bodies and operculum, with a marked increase of immunopositive cells in the growth zone of bone end-plates (Fig. $7 \mathrm{~g}, \mathrm{~h}$ ) in the notochordal cells (Fig. 7i) and the compression zone of vertebral ligaments (Fig. 7j) from deformed vertebrae. However, caspase- 3 as an immunomarker of cell apoptosis did not show such differences (data not shown). 

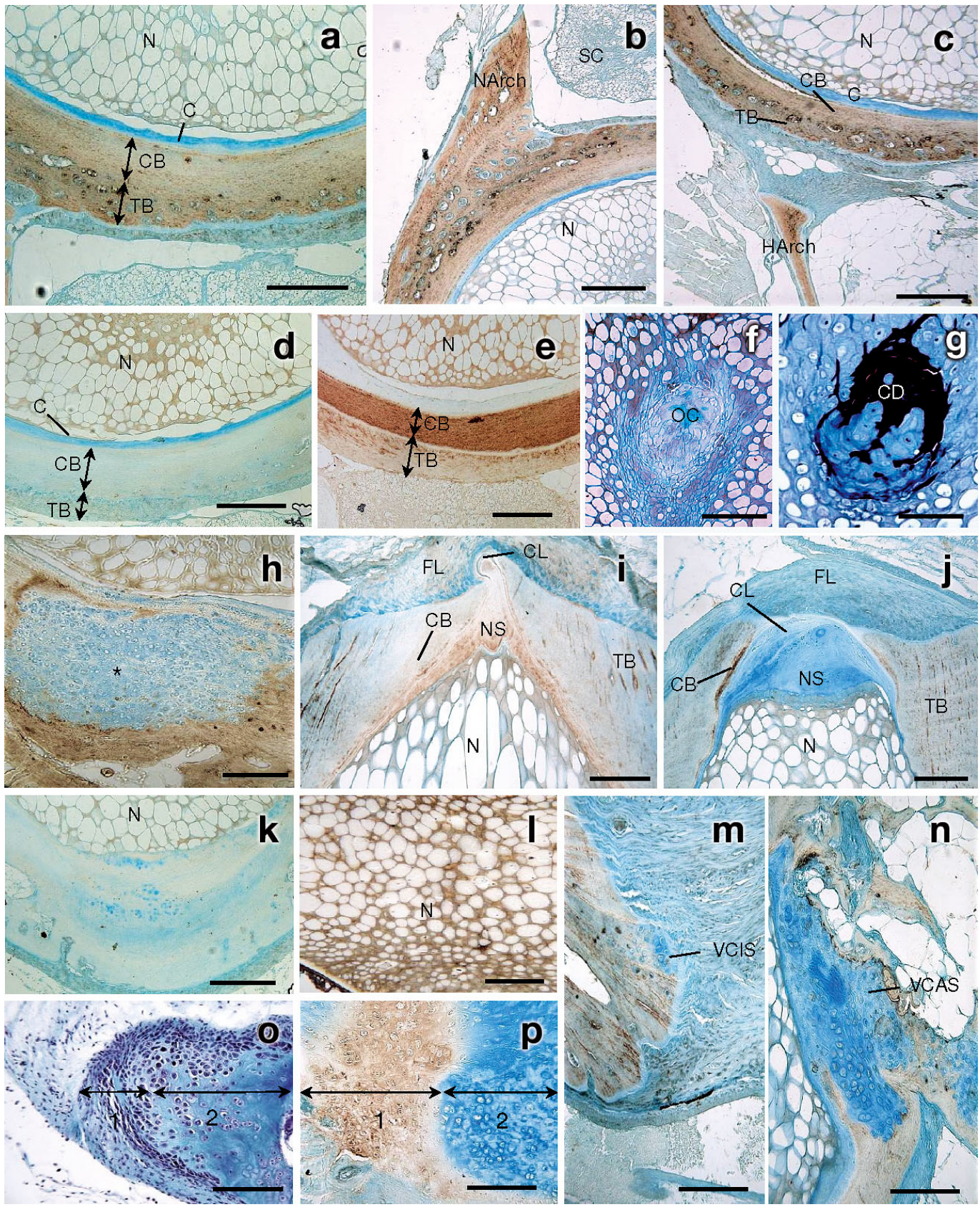

Fig. 6. Osteocalcin (OC) and matrix Gla protein (MGP) distribution counterstained with AB pH 2.5 in control and deformed vertebra of Sparus aurata. Homogeneous OC distribution both in compact and trabecular bone from the periosteal zones of (a) the vertebral centra and from (b) neural and (c) haemal arches. (d) Preferential accumulation of MGP in notochord with minimal presence in the different bone layers. Preferential accumulation of OC in (e) compact bone and (f) in notochordal cells from deformed fish coinciding with (g) a calcium deposition (von Kossa staining) in the same area. (h) Fibrous-like structure in deformed vertebra showing glycosaminoglycans (*) instead of OC deposition. (i) OC accumulation in the zone of vertebral end-plates from un-deformed fish and (j) OC deposition in the fibrous layer of the growth zone and notochordal sheath in deformed fish. (k) MGP distribution in deformed vertebra with a scarce presence of MGP in bone matrix and (l) a slight increase in staining intensity in altered notochordal cells. Detail of a compression area in the vertebral end-plates from a deformed vertebra, showing (m) initial and (n) more advanced stages in which osseous tissue is gradually replaced by cartilaginous. OC accumulation in (1) the periphery of (2) the newly formed cartilaginous tissue from the compression area (incipient vertebral fu-

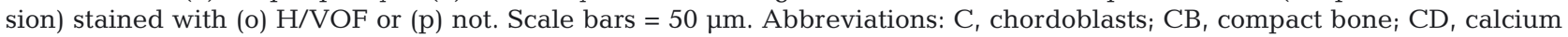
deposition; CL, collagenous ligament; FL, fibrous layer; HArch, haemal arch, N, notochord; NArch, neural arch; NS, notochordal sheath; OC, osteocalcin; SC, spinal cord; TB, trabecular bone, VCIS, vertebral compression initial stage; VCAS vertebral compression in an advanced stage 


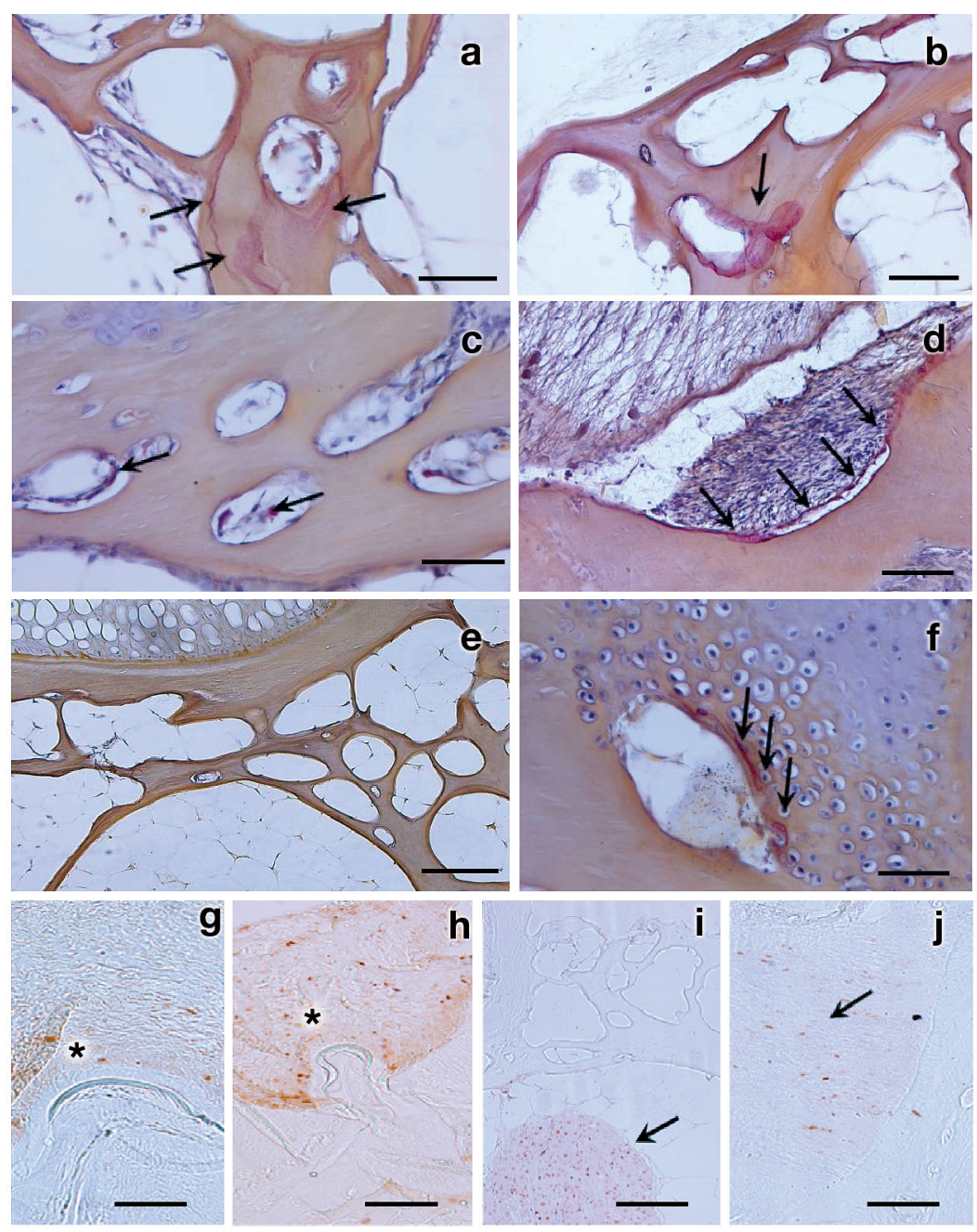

Fig. 7. (a-f) Tartrate-resistant acid phosphatase (TRAP) activity and ( $\mathrm{g}-\mathrm{j}$ ) proliferating cell nuclear antigen (PCNA) distribution in (a-d) normal and (e-f) deformed vertebra. TRAP enzymatic activity both in $(a, b)$ bone matrix (arrows) and osteoclasts (c) within trabecula and (d) in reabsorbing front. Note (e) absence of TRAP activity bone matrix in deformed vertebra and (f) the presence of enzymatic activity in the fibrous-like structures of deformed vertebra. Differences in PCNA distribution (*) in the growth zones of the vertebral end-plates from (g) normal and (h) deformed vertebra. In deformed vertebra, cell proliferation is also detected in (i) the notochordal cells and (j) in compression zone of vertebral ligament (arrows). Scale bars $=50 \mu \mathrm{m}$

Prestinicola et al. 2013). Opercular anomalies detected in gilthead sea bream juveniles were randomly distributed on both sides of the head, which was in agreement with previous data reported by Beraldo et al. (2003). The external appearance of opercular deformities found in this study were in accordance with previous studies which suggested that opercular anomalies were due to the inside folding of the opercle and subopercle bones or to their shortening/atrophy (Koumoundouros et al. 1997a, Galeotti et al. 2000, Beraldo et al. 2003, Morel et al. 2010). Histological results from our study revealed that the reduced opercular surface in the Type I deformity was mainly due to the folding of the edge of the opercle from the superior corner towards the gill chamber. The conservation of the different opercular bones that compose the operculum suggested an effect of rearing conditions during sensitive developmental periods, coinciding with the beginning of skeletogenesis of the opercular complex, which is formed by intramembranous ossification from a condensed core of mesenchymal cells (Koumoundouros et al. 1997b, Galeotti et al. 2000, Beraldo et al. 2003). Considering that the supportive tissue of the operculum was not yet formed during early development, mechanical damage (such as that caused by excessive water movement in the growing tanks) could cause the above-mentioned opercular malformations (Galeotti et al. 2000). Regarding opercular deformity Type II, our results revealed that the coalescence between opercular bone areas might have caused

\section{DISCUSSION}

In this study, the incidence of opercular anomalies in gilthead sea bream Sparus aurata was moderate (up to $6.3 \%$ ) in comparison with previously reported frequencies in farmed population of this species (up to $80 \%$; Paperna 1978, Barahona-Fernándes 1982, Chatain 1994, Andrades et al. 1996). However, such differences may be attributed to different rearing conditions and improvements in the rearing procedures over the last 2 decades (Koumoundouros 2010, semi-rigidity and tissue fusion of the opercular structures, giving the appearance of underdeveloped or incomplete tissue. Depending on the dissected region (articulatory facet, medial or ventral zone), underdevelopment of the opercle, subopercle and/or both were clearly visible. Sectioning the ventral zone of the operculum showed a regression of the subopercle and a complete loss of the opercle, although the covering tissue layers of this skeletal structure were maintained and folded into the gill cavity. Furthermore, opercular sectioning at the medial level showed 
an outward folding of the opercle and a thickening of the epithelial cell layers. According to Galeotti et al. (2000), the above-mentioned opercular disorders might be mechanically-induced by forced opercular movements occurring during ventilation or food ingestion processes, although the putative involvement of nutritional factors and/or environmental pollutants should not be neglected (Boglione et al. 2013a).

Specimens displaying the opercular Type II deformity also showed a novel type of opercular anomaly that consisted of a coalescence of contacting bone tissues, presumably from the preopercle and opercle. The above-mentioned anomaly had a trabecular aspect filled by a single cell epithelium of cubic osteoblastic-like cells. The origin of this anomaly might be a disorganization of the blastema (aggregate of mesenchymal cells), the precursor of the opercular elements formed by intramembranous ossification at early developmental stages, brought about as a result of inadequate rearing conditions such as unbalanced diet, inadequate aeration or unfavourable temperature during the embryonic and larval stage (Loizides et al. 2013). Regardless of the cause of these types of deformities, there is evidence that opercular abnormalities compromise the welfare (Noble et al. 2012) and product quality (Cobcroft \& Battaglene 2013) of the fish stock, as well as the biological performance of the fish, reducing their resistance to oxygen stress and predisposing the gills to pathological infections (Koumoundouros et al. 1997b). Moreover, a clear connection has been established between opercular or vertebral abnormalities and high mortality rates (Andrades et al. 1996, Loizides et al. 2013).

Opercular bones stained with picrosirius red were visualized under polarized light, which enhances the normal birefringence of collagen fibers. The birefringence colour appears to be a measure of the thickness of the collagen fibers, the density of their packing and their spatial arrangement. As fiber thickness increases, their colour changes from green (thinner collagen fibers) to bright orange/red (larger collagen fibers; Junqueira et al. 1982, Hiss et al. 1988, Dayan et al. 1989). Thus, we were able to determine potential differences in ECM composition. In nondeformed opercula, this technique showed 2 populations of collagen fibers: one group of orange, strongly birefringent fibres (thick collagen fibers) and another group of green, weakly birefringent fibers (thin fibers). A comparison between normal and deformed opercula revealed differences in collagen fiber thickness and in their 3-dimensional arrangement, consisting of reduced and scattered areas of orange dye (fewer big collagen fibers) in deformed opercular bones (opercle and subopercle). This fact has been suggested as a bone remodelling process linked to changes in bone composition and degradation of collagen fibers (Fernández et al. 2012). Considering that the mechanical properties of the opercular bone depend on the composition and structure of its matrix (Totland et al. 2011), the thickness of collagen fibers in deformed opercula might indicate a weakness and vulnerability to mechanical disturbances of this skeletal structure, since collagen content confers certain tissue elasticity (Prades et al. 2010), and therefore changes in its proportion could reduce tissue flexibility and plasticity (Canavese \& Colitti 1996, Ytteborg et al. 2012).

Vertebral column malformations may occur frequently in the wild, but are rarely detected (Gavaia et al. 2009) whereas they are quite commonly detected under intensive aquaculture conditions (Kranenbarg et al. 2005, Koumoundouros 2010, Prestinicola et al. 2013, among others). In this study, the frequency of lordotic vertebrae $(10.1 \%)$ was within the normal range found in other studies and hatcheries (Andrades et al. 1996, Koumoundouros et al. 2002, Prestinicola et al. 2013). The aetiology of this skeletal disorder might vary depending on the rearing and environmental conditions (see reviews in Koumoundouros 2010, Boglione et al. 2013a). Independent of the causative factor, lordosis may occur at different developmental stages. For instance, some authors have reported that vertebral deformities may appear during the notochord segmentation and vertebral centrum differentiation processes (Fernández et al. 2008, Haga et al. 2009). Others have suggested that they are a consequence of dysfunctions in collagen metabolism at notochordal and perinotochordal collagen sheets during early development (Sanatamaría et al. 1994). Moreover, vertebral deformities may also occur later in ontogeny (i.e. during the ongrowing period), at which point they are generally induced by mechanical overloads (Kranenbarg et al. 2005) or by the curvature of the vertebral axis (Gorman et al. 2010), or a combination of both (Gavaia et al. 2002, Cardeira et al. 2012). Irrespective of the cause of vertebral anomalies, they can compromise the biological performance of fish. For example, in European sea bass, pre-haemal kyphosis was shown to induce lethargic behaviour and subsequent heavy mortality during vertebral axis osteogenesis, as a result of the compression of the neural tube by the deformed vertebrae (Koumoundouros et al. 2002). Furthermore, Basaran et al. (2007) showed that lordosis significantly decreased the endurance and crit- 
ical swimming speed in European sea bass juveniles. In the present study, gilthead sea bream lordotic vertebrae showed the formation of fibrous cartilage in the haemal and/or neural sides of the vertebral centrum. This chondroid tissue might meet the demand for an accelerated growth rate and/or the demand for a shear-resistant support (Huysseune 2000, Cardeira et al. 2012). Moreover, in the central notochord of affected vertebrae, regions of densely packed chordocytes lacking vacuoles were also observed, whereas calcium deposition within de-vacuolated chordocytes was detected as reported in salmonids (Ytteborg et al. 2012). Thus, the change in chordocyte morphology from vacuolated to hyperdense, and the increase in calcium deposition in the affected region of gilthead sea bream lordotic vertebrae might indicate that a metaplastic shift was involved, as it has been previously described in spinal fusions in fish (Witten et al. 2005, Ytteborg et al. 2012, Boglione et al. 2013b). Another major histomorphological change in lordotic gilthead sea bream vertebrae was the disorganization of the intervertebral region, which lead to a complete loss of notochordal sheath integrity. These results were in concordance with those reported by other authors for Atlantic salmon Salmon salar reared at high temperatures (Ytteborg et al. 2010), gilthead sea bream fed hypervitaminosis A (Fernández et al. 2012) and guppy Poecilia reticulata displaying a curveback syndrome (Gorman et al. 2010). Major histomorphological changes of lordotic vertebrae in gilthead sea bream specimens from this study were linked to the loss of the integrity of notochordal cells, which was associated with the presence of modified chordocytes in which calcium deposition was noticeable. Similarly, Loizides et al. (2013) pointed out the ectopic presence of altered chordocytes as well as increased notochordal sheath production as the causes of the vertebral compression and fusion (VCF) syndrome in gilthead sea bream.

PCNA immunohistochemistry indicated that osteoblasts in the growth zone of the bone end-plates showed a marked increase in cell proliferation in deformed vertebral centra, which was not counteracted by an increase in cell death as revealed by caspase- 3 immunostaining. In addition, a marked increase in cell proliferation (PCNA staining), but not of cell apoptosis was also detected in notochordal cells and in the compression zone of vertebral ligament in lordotic vertebrae. Several studies in higher vertebrates have suggested that changes in the balance between cell death and cell proliferation are involved in bone and cartilage defects, which could ultimately lead to skeletal deformities (Cockroft
\& New 1978, Miura et al. 2004). In this sense, the above-mentioned imbalanced cell cycling detected in lordotic vertebrae might also explain the presence of dense packaged chordocytes, occupying most of the intervertebral space without vacuolation, as was described by Ytteborg et al. (2010) in Atlantic salmon vertebral fusions. Regarding the bone homeostasis measured by ALP and TRAP immunostaining, although this procedure may not be considered to be a quantitative assessment of bone formation and resorption, the present data might indicate that lordotic vertebrae were subjected to a more localized bone resorption process than non-deformed ones, since TRAP activity was only found in the chondrocytic areas of deformed vertebrae but was homogeneously distributed in the trabecular spaces of normal vertebrae. Local and intense TRAP activity in deformed vertebrae is in agreement with the reduced thickness of collagen fibers and the previously suggested bone remodelling process occurring in this deformed skeletal structure. These results differ from those previously described in spinal fusions by Ytteborg et al. (2012) and Boglione et al. (2013b).

In the vertebral growth zones of the teleosts, ECMproducing cells (osteoblasts and bone lining cells) express a combination of proteins having distinct functions in mineralisation and/or deposition of the osteoid (Krossøy et al. 2009, Boglione et al. 2013b). Among these proteins, OC and MGP have been reported to be involved in the mineralization of the ECM. In this sense, OC has been proposed as a regulator of bone maturation (Krossøy et al. 2009), whereas MGP acts as an inhibitor of calcification (Luo et al. 1997). In this study, a preferential accumulation of $\mathrm{OC}$ in compact bone and notochordal cells of lordotic vertebrae was detected, which might be attributed to the remodelling process occurring in lordotic vertebrae (Boglione et al. 2013b) as well as the above-mentioned cartilage formation by metaplasic transformation of bone, forming cells that would be latter mineralized and remodelled into bone (Witten et al. 2005). Concerning MGP, a preferential deposition was detected in notochordal cells of non-deformed vertebrae compared with deformed ones. Higher levels of OC and MGP deposition in notochordal tissue of deformed vertebrae were similar to those reported by Fernández et al. (2012) in gilthead sea bream juveniles fed hypervitaminosis A. These results are in agreement with previous studies in which an increased co-transcription of both chondrogenic and osteogenic markers were found in the notochord of Atlantic salmon displaying spinal fusions (Ytteborg et al. 2010, 2012). Furthermore, bone tissue 
with lower levels of OC might demineralize more easily than that with higher OC content (Krossøy et al. 2009), suggesting that lordotic vertebrae may be more fragile than non-deformed ones. However, this hypothesis requires further corroboration by additional mineral content analyses.

\section{CONCLUSIONS}

This study provided a comprehensive description of the main morphological and histological features of normal and deformed opercula and vertebrae from gilthead sea bream in order to increase basic knowledge of bone disorders in this species. Our data revealed that important histological, histochemical and immunohistochemical differences were found between non-deformed and deformed opercula and vertebrae. A rare type of tissue remodelling process was described in fish displaying the Type II opercular deformity, which consisted of the coalescence of contacting bone tissues, presumably from the preopercle and opercle, resulting in skeletal tissue with a trabecular aspect filled by a single cell epithelium of cubic osteoblastic-like cells. Additionally, there were differences in collagen fiber thickness and 3-dimensional arrangement between normal and deformed opercula, as well as hypoplasia of muscle fibers, which might affect the flexibility of deformed opercula. Lordotic gilthead sea bream vertebrae showed the formation of fibrous cartilage in their haemal and/or neural sides, indicating that a metaplastic shift occurred during the process of lordosis. Another major histomorphological change in lordotic vertebrae was the complete loss of notochordal sheath integrity. These alterations were coupled with an imbalance between cell death and cell proliferation processes in lordotic vertebrae, as well as in bone formation/resorption and ECM deposition activity, which might have resulted from the remodelling process occurring in lordotic vertebrae. Altogether, these results provide an increase in the basic knowledge of bone disorders that will add to our understanding of the mechanisms by which these skeletal disorders appear in this fish species and which hamper its production efficiency.

Acknowledgements. The authors express their gratitude to I. Viaña for providing technical assistance and to Dr. D. Simes for providing the OC and MGP antibodies. This work was funded by Ministry of Science and Innovation (MICIIN) of the Spanish government (projects AGL2008-03897-C01/ C04 and AGL2010-15951). J.B.O-D. was supported by the Programa Ramón y Cajal (MICINN, Spain). I.F. was sup- ported by a predoctoral Spanish MICINN fellowship (reference, BES- 2006-12650) and a postdoctoral fellowship (SFRH/BDP/82049/2011) from Fundação para a Ciência e Tecnologia (FCT), Portugal.

\section{LITERATURE CITED}

> Andrades JA, Becerra J, Fernández-Llebrez P (1996) Skeletal deformities in larval, juvenile and adult stages of cultured gilthead sea bream (Sparus aurata L.). Aquaculture 141:1-11

Bakke-McKellep AM, Froystad MK, Lilleeng E, Dapra F, Refstie S, Krogdahl A, Landsverk T (2007) Response to soy: T-cell-like reactivity in the intestine of Atlantic salmon, Salmo salar L. J Fish Dis 30:13-25

Bancroft JD, Stevens A (1990) Theory and practice of histological techniques. Churchill Livingstone, London

Barahona-Fernándes MH (1982) Body deformation in hatchery reared European sea bass Dicentrachus labrax (L). Types, prevalence and effect on fish survival. J Fish Biol 21:239-249

> Basaran F, Ozbilgin H, Ozbilgin YD (2007) Effect of lordosis on the swimming performance of juvenile sea bass (Dicentrarchus labrax L.). Aquacult Res 38:870-876

Beraldo P, Pinosa M, Tibaldi E, Canavese B (2003) Abnormalities of the operculum in gilthead sea bream (Sparus aurata): morphological description. Aquaculture 220: 89-99

> Boglione C, Gagliardi F, Scardi M, Cataudella S (2001) Skeletal descriptors and quality assessment in larvae and post-larvae of wild-caught and hatchery-reared gilthead sea bream (Sparus aurata L. 1758). Aquaculture 192:1-22

Boglione C, Gisbert E, Gavaia P, Witten PE, Moren M, Fontagné S, Koumoundouros G (2013a) A review on skeletal anomalies in reared European larvae and juveniles. Part 2: Main typologies, occurrences and causative factors. Rev Aquac 5:S121-S167

Boglione C, Gavaia P, Koumoundouros G, Gisbert E, Moren M, Fontagné S, Witten PE (2013b) A review on skeletal anomalies in reared European fishes. Part 1: Normal and anomalous skeletogenic processes. Rev Aquac 5: S99-S120

Bonewald LF, Harris SE, Rosser J, Dallas MR and others (2003) Von Kossa staining alone is not sufficient to confirm that mineralization in vitro represents bone formation. Calcif Tissue Int 72:537-547

Canavese B, Colitti M (1996) Observations under LM and SEM of opercle malformations in sea bream (Sparus aurata). Teratology 53:27A (Abstract)

Cardeira J, Bensimon-Brito A, Pousão-Ferreira P, Cancela ML, Gavaia PJ (2012) Lordotic-kyphotic vertebrae develop ectopic cartilage-like tissue in Senegalese sole (Solea senegalensis). J Appl Ichthyology 28:460-463

> Castro J, Pino-Querido A, Hermida M, Chavarrias D and others (2008) Heritability of skeleton abnormalities (lordosis, lack of operculum) in gilthead seabream (Sparus aurata) supported by microsatellite family data. Aquaculture 279:18-22

- Chatain B (1994) Abnormal swimbladder development and lordosis in sea bass (Dicentrachus labrax) and sea bream (Sparus aurata). Aquaculture 119:371-379

Clark G (1981) Staining procedures. Williams \& Wilkins, Baltimore, MD

> Cobcroft JM, Battaglene SC (2013) Skeletal malformations 
in Australian marine finfish hatcheries. Aquaculture 396399:51-58

> Cockroft DL, New DAT (1978) Abnormalities induced in cultured rat embryos by hypertermia. Teratology 17: 277-283

Daoulas C, Economou AN, Bantavas I (1991) Osteological abnormalities in laboratory reared sea-bass (Dicentrarchus labrax) fingerlings. Aquaculture 97:169-180

> Dayan D, Hiss Y, Hirshberg A, Bubis JJ, Wolman M (1989) Are the polarization colors of Picrosirius red-stained collagen determined only by the diameter of the fibers? Histochemistry 93:27-29

> Diggles BK (2013) Saddleback deformities in yellowfin bream, Acanthopagrus australis (Günther), from South East Queensland. J Fish Dis 36:521-527

Faustino M, Power DM (1998) Development of osteological structures in the sea bream: vertebral column and caudal fin complex. J Fish Biol 52:11-22

Faustino M, Power DM (1999) Development of the pectoral, pelvic, dorsal and anal fins in cultured sea bream. J Fish Biol 54:1094-1110

Faustino M, Power DM (2001) Osteologic development of the viscerocranial skeleton in sea bream: alternative ossification strategies in teleost fish. J Fish Biol 58:537-572

Fernández I, Hontoria F, Ortiz-Delgado JB, Kotzamanis Y, Estévez A, Zambonino-Infante J, Gisbert E (2008) Larval performance and skeletal deformities in farmed gilthead sea bream (Sparus aurata) fed with graded levels of Vitamin A enriched rotifers (Brachionus plicatilis). Aquaculture 283:102-115

> Fernández I, Ortiz-Delgado JB, Sarasquete C, Gisbert E (2012) Vitamin A effects on vertebral bone tissue homeostasis in gilthead sea bream (Sparus aurata) juveniles. J Appl Ichthyology 28:419-426

Galeotti M, Beraldo P, de Dominis S, D'Angelo L and others (2000) A preliminary histological and ultrastructural study of opercular anomalies in gilthead sea bream larvae (Sparus aurata). Fish Physiol Biochem 22:151-157

Gavaia PJ, Dinis MT, Cancela ML (2002) Osteological development and abnormalities of the vertebral column and caudal skeleton in larval and juvenile stages of hatcheryreared Senegal sole (Solea senegalensis). Aquaculture 211:305-323

Gavaia PJ, Domingues S, Engrola S, Drake P, Sarasquete C, Dinis MT, Cancela ML (2009) Comparing skeletal development of wild and hatchery-reared Senegalese sole (Solea senegalensis, Kaup 1985): evaluation in larval and postlarval stages. Aquacult Res 40:1585-1593

Gorman KF, Handrigan GR, Jin G, Wallis R, Breden F (2010) Structural and micro-anatomical changes in vertebrae associated with idiopathic-type spinal curvature in the curveback guppy model. Scoliosis 5:10

Gutiérrez M (1967) Coloración histológical para ovarios de peces, crustáceos y moluscos. Inv Pesq 31:265-271

> Haga Y, Dominique VJ, Du SJ (2009) Analyzing notochord segmentation and intervertebral disc formation using the twhh:gfp transgenic zebrafish model. Transgenic Res 18: 669-683

Hiss J, Hirshberg A, Fundoiano-Dayan D, Bubis JJ, Wolman $H$ (1988) Aging of wound healing in an experimental model in mice. Am J Forensic Med Pathol 9:310-312

Huysseune A (2000) Skeletal system. In: Ostrander GK (ed) The laboratory fish. Academic Press, San Diego, CA, p 307-317

> Junqueira LCU, Bignolas G, Brentani RR (1979) Picrosirius staining plus polarization microscopy, a specific method for collagen detection in tissue sections. Histochem J 11: $447-455$

Junqueira LCU, Montes GS, Sanchez EM (1982) The influence of tissue sections thickness on the study of collagen by the picrosirius-polarization method. Histochemistry 74:153-156

Karsenty G (2001) Transcriptional control of osteoblast differentiation. Endocrinology 142:2731-2733

Kiernan JA (2008) Methods for connective tissue. In: Kiernan JA (ed) Histological and histochemical methods: theory and practice, 4th edn. Scion, Bloxham, p 190-213

Koumoundouros G (2010) Morpho-anatomical abnormalities in Mediterranean marine aquaculture. In: Koumoundouros G (ed) Recent advances in aquaculture research. Transworld Research Network, Kerala, p 125-148

Koumoundouros G, Gagliardi F, Divanach P, Boglione D, Cataudella S, Kentouri M (1997a) Normal and abnormal osteological development of caudal fin in Sparus aurata L. fry. Aquaculture 149:215-226

Koumoundouros G, Oran G, Divanach P, Stefanakis S, Kentouri $M(1997 b)$ The opercular complex deformity in intensive gilthead sea bream (Sparus aurata L.) larviculture. Moment of apparition and description. Aquaculture 156:165-177

Koumoundouros G, Maingot E, Divanach P, Kentouri M (2002) Kyphosis in reared sea bass (Dicentrarchus labrax L.): ontogeny and effects on mortality. Aquaculture 209: 49-58

Kranenbarg S, Waarsing JH, Muller M, Weinans $\mathrm{H}$, van Leeuwen JL (2005) Lordotic vertebrae in sea bass (Dicentrarchus labrax L.) are adapted to increased loads. J Biomech 38:1239-1246

Krossøy C, Ornsrud R, Wargelius A (2009) Differential gene expression of bgp and mgp in trabecular and compact bone of Atlantic salmon (Salmo salar L.) vertebrae. J Anat 215:663-672

> Loizides M, Georgiou AN, Somarakis S, Witten PE, Koumoundouros G (2013) A new type of lordosis and vertebral body compression in Gilthead seabream (Sparus aurata Linnaeus, 1758): aetiology, anatomy and consequences for survival. J Fish Dis, doi:10.1111/jfd.12189

> Luo G, Ducy P, Mckee MD, Pinenro GJ, Loyer E, Behringer RR, Karsenty G (1997) Spontaneous calcification of arteries and cartilage in mice lacking matrix GLA protein. Nature 386:78-81

Martoja R, Martoja-Pierson M (1970) Técnicas de histología animal. Toray-Masson, Barcelona

Meunier FJ (2011) The osteichtyes, from the paleozoic to the extant time, through histology and palaeohistology of bony tissues. C R Pal 10:347-355

Miura M, Chen XD, Allen MR, Bi YM, Gronthos S, Seo BM (2004) A crucial role of caspase-3 in osteogenic differentiation of bone marrow stromal stem cells. J Clin Invest 114:1704-1713

> Morel C, Adriaens D, Boone M, De Wolf T, Van Hoorebeke L, Sorgeloos P (2010) Visualizing mineralization in deformed opercular bones of larval gilthead sea bream (Sparus aurata). J Appl Ichthyology 26:278-279

Noble C, Cañon Jones H, Damsgård B, Flood M and others (2012) Injuries and deformities in fish: their potential impacts upon aquacultural production and welfare. Fish Physiol Biochem 38:61-83

Ortega A (2008) Cultivo de Dorada (Sparus aurata). In: Espinosa de los Monteros J (ed) Cuadernos de Acuicul- 
tura. Fundación Observatorio Español de Acuicultura, Madrid

Ortiz-Delgado JB, Simes DC, Gavaia P, Sarasquete C, Cancela ML (2005) Osteocalcin and matrix GLA protein in developing teleost teeth: identification of sites of mRNA and protein accumulation at single cell resolution. Histochem Cell Biol 124:123-130

Paperna I (1978) Swimbladder and skeletal deformation in hatchery bred Sparus aurata. J Fish Biol 12:109-114

Pearse AGE (1985) Histochemistry: theoretical and applied, 4th edn. Vol 2: analytical technology. Churchill Livinstone, Edinburgh

> Prades JM, Dumollard JM, Duband S, Timoshenko A and others (2010) Lamina propria of the human vocal fold: histomorphometric study of collagen fibers. Surg Radiol Anat 32:377-382

Prestinicola L, Boglione C, Makridis P, Spanò A and others (2013) Environmental conditioning of skeletal anomalies typology and frequency in gilthead seabream (Sparus aurata L., 1758) juveniles. PLoS ONE 8:e55736

Sanden M, Berntssen MHG, Krogdahl A, Hemre GI, BakkeMcKellep AM (2005) An examination of the intestinal tract of Atlantic salmon, Salmo salar L., parr fed different varieties of soy and maize. J Fish Dis 28:317-330

Sanatamaría JA, Andrades JA, Herráez P, FernándezLlebrez P, Becerra J (1994) Perinotochordal connective sheet of gilthead sea bream larvae (Sparus aurata, L.) affected by axial malformations: a histochemical and immunocytochemical study. Anat Rec 240:248-254

Sarasquete C, Gutiérrez M (2005) New tetrachromic VOF stain (Type III-G.S) for normal and pathological fish tissues. Eur J Histochem 49:105-114

Simes DC, Williamson M, Ortiz-Delgado JB, Viegas SCB, Price PA, Cancela ML (2003) Purification of matrix Gla protein from a marine teleost fish, Argyrosomus regius: calcified cartilage and not bone as the primary site of MGP accumulation in fish. J Bone Miner Res 18:244-259

Simes DC, Williamson M, Schaff BJ, Gavaia PJ, Ingleton

Editorial responsibility: Christine Paetzold, Oldendorf/Luhe, Germany
PM, Price PA, Cancela ML (2004) Charaterization of osteocalcin (BGP) and matrix Gla protein (MGP) fish specific antibodies: validation for immunodetection studies in lower vertebrates. Calcif Tissue Int 74:170-180

> Tiago DM, Laizé V, Bargelloni L, Ferraresso S, Romualdi C, Cancela ML (2011) Global analysis of gene expression in mineralizing fish vertebra-derived cell lines: new insights into anti-mineralogenic effect of vanadate. BMC Genomics 12:310

Totland GK, Fjelldal PG, Kryvi H, Løkka G and others (2011) Sustained swimming increases the mineral content and osteocyte density of salmon vertebral bone. J Anat 219: 490-501

> Verhaegen Y, Adriaens D, De Wolf T, Dhert P, Sorgeloos P (2007) Deformities in larval gilthead sea bream (Sparus aurata): a qualitative and quantitative analysis using geometric morphometrics. Aquaculture 268:156-168

> Witten PE, Gil-Martens L, Hall BK, Huysseune A, Obach A (2005) Compressed vertebrae in Atlantic salmon Salmo salar: evidence for metaplastic chondrogenesis as a skeletogenic response late in ontogeny. Dis Aquat Org 64:237-246

> Witten PE, Obach A, Huyseune A, Baeverfjord G (2006) Vertebrae fusion in Atlantic salmon (Salmo salar): development aggravation and pathways of containment. Aquaculture 258:164-172

> Witten PE, Gil-Martens L, Huysseune A, Takle H, Hjelde K (2009) Towards a classification and an understanding of developmental relationships of vertebral body malformations in Atlantic salmon (Salmo salar L.). Aquaculture 295:6-14

> Ytteborg E, Baeverfjord G, Torgersen J, Hjelde K, Takle H (2010) Molecular pathology of vertebral deformities in hyperthermic Atlantic salmon (Salmo salar). BMC Physiol 10:12

Ytteborg E, Baeverfjord G, Takle H (2012) Four stages characterizing vertebral fusions in Atlantic salmon. J Appl Ichthyology 28:453-459

Submitted: September 16, 2013; Accepted: April 14, 2014

Proofs received from author(s): June 5, 2014 